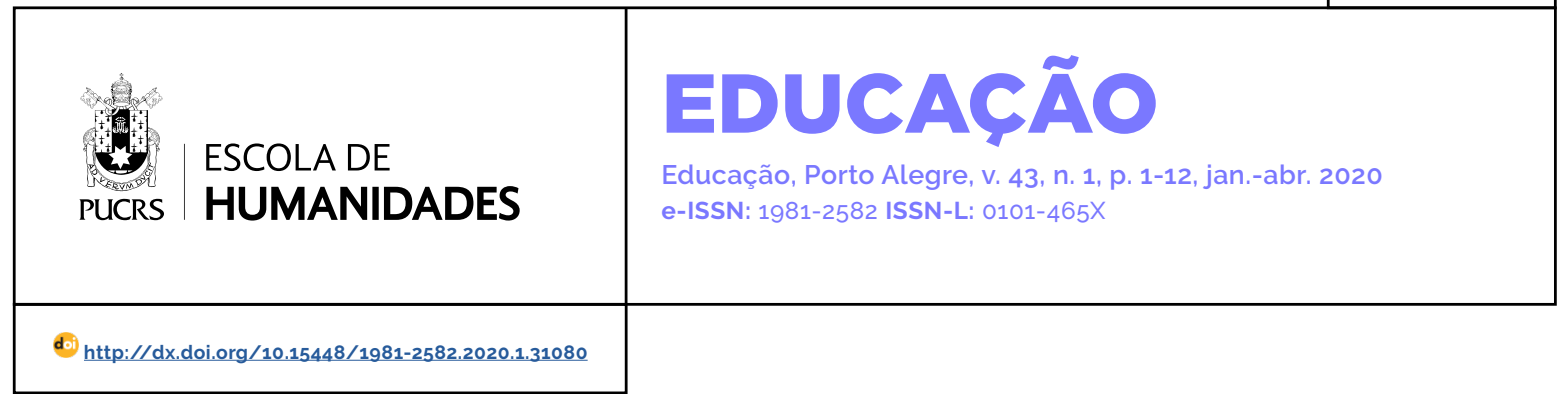

OUTROS TEMAS

\title{
Ser criança indígena terena no espaço da cidade: cultura, escola e brincadeira
}

Be a terena indigenous child in city area: culture, school and play Ser niño indigena terena en el espacio de la ciudad: cultura, escuela y brincador

\section{Carlos Magno Naglis \\ Vieira $^{1}$ \\ orcid.org/0000-0003-4004-4836 cmhist@hotmail.com}

Adir Casaro Nascimento orcid.org/0000-0002-7488-6022 adir@ucdb.br

Recebido em: 15 ago. 2018 Aprovado em: 17 jan. 2020. Publicado em: Xx XXX. 2020.
Resumo: Com o objetivo de apresentar as crianças indigenas Terena de duas aldeias indigenas urbanas da cidade de Campo Grande/MS, mostrando os lugares por onde circulam, as culturas que produzem e ressignificam, as brincadeiras que realizam, os conflitos e as tensões no espaço urbano (aldeias urbanas e escola), o artigo que parte das experiências de pesquisas dos autores, elabora reflexões em uma temática que ainda desperta pouco interesse, apesar de nos últimos anos se verificar um crescimento tímido sobre produções desse outro espaço de vivência de criança indígenas. Nesse sentido, o estudo que está marcado pelo pensamento de autores que se situam na convergência entre os estudos da Antropologia da Criança, das teorias pós-coloniais e dos estudos de Cultura, pretende criar visibilidade para futuros debates envolvendo uma temática, ainda vista como marginalizada, subordinada e silenciada no espaço da academia.

Palavras-chave: criança indigena, cidade, escola, brincadeiras.

Abstract: This paper aims to present the Terena indigenous children from two urban villages of Campo Grande / MS, showing the places where they circulate, the cultures they produce and resignify, the games they play, the conflicts and tensions in the urban area (urban villages and schools). The present paper starts from the experiences researches by the authors, still elaborates reflections in a theme that arouses little interest, although in the last years there is a small growth, about productions of this other space of experience of indigenous children. In this sense, the study that is marked by the thought of authors who locate in the convergence between the studies of Child Anthropology, postcolonial theories and culture studies, aims to create visibility for future debates involving a theme. still seen as marginalized, subordinate and silenced in the academic field.

Keywords: indigenous child, city, school, play.

Resumen: Para presentar a los niños indígenas Terena de dos pueblos indigenas urbanos en la ciudad de Campo Grande / MS, mostrando los lugares donde circulan, las culturas que producen y resignifican, los juegos que juegan, los conflictos y las tensiones en el espacio urbano (pueblos áreas urbanas y escuela), el artículo que parte de las experiencias de investigación de los autores, elabora reflexiones sobre un tema que aún despierta poco interés, aunque en los últimos años ha habido un crecimiento aún tímido en las producciones de este otro espacio de experiencia de niños indígenas. En este sentido, el estudio que está marcado por el pensamiento de los autores que se ubican en la convergencia entre los estudios de Antropología Infantil, las teorias poscoloniales y los estudios culturales, tiene como objetivo crear visibilidad para futuros debates que involucren un tema, aún visto como marginado, subordinado y silenciado en el espacio de la academia.

Palabras clave: niño indígena, ciudad, escuela, juego. 
Os estudos sobre criança e infância nos mostram que estamos diante de um tema em construção e ressignificação, que caminha por diferentes epistemologias. Além da dificil tarefa de compreender os discursos e as teorizações que tentam elaborar explicações para ajudar a entender as situações desse grupo, o pesquisador necessita de muita dedicação, atenção, ousadia para se aventurar e adentrar no assunto e de percepção para verificar o quanto "a criança subverte a ordem e, com seu olhar, revela outra maneira de enxergar o real" (Kramer, 2010, p. 190).

Assim, a partir de idas e vindas, observações e experiências que nos marcaram e tocaram, tivemos a oportunidade de problematizar e delinear os nossos olhares e, com isso, ressignificar a nossa percepção da criança indigena em contexto urbano e do seu cotidiano. Realizado esse trajeto, de aproximadamente três anos, conseguimos uma melhor aproximação dos lugares por onde essas crianças transitam, as culturas que produzem e desconstroem, as tensões e os conflitos no espaço escolar e, ainda, verificar a sua participação em atividades e brincadeiras que realizam. Segundo Vieira (2015) amparado em Cohn (2005), todo esse procedimento é preciso para entender o mundo em que a criança indígena está inserida e o modo como experimenta e se expressa na vida social.

Nessa mesma direção, Cohn (2005) nos ajuda a pensar que "não podemos falar de crianças de um povo indígena sem entender como esse povo pensa o que é ser criança e sem entender - lugar que elas ocupam naquela sociedade" (p. 9). Nesse sentido, partindo das experiências dos autores e das reflexões do projeto de pesquisa "A cosmovisão e as representações das crianças indígenas no Mato Grosso do Sul: as relações entre a pedagogia do cotidiano e a escola"2, vinculado ao grupo de pesquisa/ CNPq - Educação e Interculturalidade, do Programa de Pós-Graduação em Educação Mestrado e Doutorado da Universidade Católica Dom Bosco/UCDB, o artigo tem como objetivo apresentar as crianças indigenas Terena na cidade de Campo Grande/MS, mostrando os lugares por onde circulam, as culturas que produzem e ressignificam, as brincadeiras que realizam e os conflitos e as tensões no espaço escolar urbano.

Campo Grande, capital de Mato Grosso do Sul, apresenta um contexto indigena com diferentes etnias residindo no município. Além da população Terena que concentra o maior quantitativo populacional, estão presentes os indios da etnia Guarani, Kaiowá, Kadiwéu, Kiniquinau, Xavante e Bororo. Essa população está distribuída em diferentes aldeias indígenas urbanas, ou seja, são loteamentos habitacionais onde reside um número expressivo de famílias indígenas, que compõem uma rede de parentesco, regras e relações (Vieira, 2015).

Para esse texto, os nossos olhares e o exercicio da escrita foram direcionados para duas aldeias indigenas urbanas de Campo Grande/MS: a aldeia indigena urbana Marçal de Souza e a aldeia indigena urbana Darci Ribeiro. A aldeia indígena urbana Marçal de Souza foi a primeira comunidade a ser constituida em Campo Grande, no ano de 1995, e possui, aproximadamente, 115 casas e cerca de 500 moradores. A aldeia indigena urbana Darci Ribeiro foi formada em 2006, em região próxima a um presídio de segurança máxima. A comunidade indigena possui aproximadamente 300 pessoas residindo no local.

Durante o periodo de pesquisa, algumas conversas foram realizadas com os Terena que residem nas aldeias indigenas urbanas mencionadas. Nesse texto, essas conversas serão registradas a partir de indio Terena 1, índio Terena 2 e 3. Esse procedimento se faz necessário para manter o princípio ético de pesquisa e preservar os moradores das aldeias urbanas de Campo Grande/MS.

Sensibilizados, borrados e marcados pelo pensamento de autores que se situam na convergência entre os estudos da Antropologia da Criança, das teorias pós-coloniais e dos estudos de Cultura e que a todo o momento nos direciona a uma "vigilância epistemológica" do desaprender,

\footnotetext{
O projeto de pesquisa contou com o financiamento do Conselho Nacional de Desenvolvimento Científico e Tecnológico/CNPq no período de 2013 a 2017.
} 
do desconstruir e do ressignificar a modernidade racional, o texto nos proporciona uma discussão sobre o contexto das populações indígenas na cidade e, depois, apresenta o cotidiano da criança indigena em contexto urbano, apontando os elementos culturais, as brincadeiras e a presença delas no espaço escolar.

\section{As populações indígenas na cidade: apresentando o contexto}

A população indigena brasileira na cidade é cerca de 315 mil índios, segundo os dados do Instituto Brasileiro de Geografia e Estatística (IBGE, 2010). Com base em estudos sobre a temática, as produções sobre o assunto não apresentam um consenso com relação a que termo empregar: índios urbanos, índios na cidade, índios da cidade, índios citadinos, indios em área urbana e índios em contexto urbano (Albuquerque, 2011; Silva, 2015; Vieira, 2015).

Além desses modelos de classificação, ainda, muito encontrados em trabalhos acadêmicos para denominar a presença de índios no espaço urbano, ou seja, fora das Terras Indigenas 3 (TI), o termo "índios desaldeados" se faz presente. De acordo com Vieira (2015) apoiado nos estudos de Albuquerque (2011), observamos que esse modo de denominar os índios na cidade, além de simplista, não é suficiente para compreender a complexidade da questão. Ainda de acordo com os autores, isso se torna evidente pelo fato de não haver uma legislação de assistência às populações indigenas na cidade, pois o que presenciamos como politicas públicas para indigenas nas áreas de saúde, educação e moradia se refere e está vinculado ao atendimento das populações que residem nos territórios indigenas e não no perímetro urbano.

O fato de o Governo Federal não elaborar leis que amparam as populações indígenas em contexto urbano pode ser entendido como estratégia para manter esses povos invisiveis e, de alguma forma, silenciados. Com essa prática de controle, o governo procura manter nas cidades bons cidadãos, ou seja, "identidades homogêneas que tornem viável o projeto moderno da governamentalidade" (Castro-Gomez, 2005, p. 81). Ainda, contribui para a colonialidade de silenciar o "outro", o que corrobora o pensamento moderno, que legitima apenas um conhecimento, escuta apenas um lado e reforça o imaginário de que se trataria de uma população habitante de floresta, preguiçosa e incapaz de viver nas cidades.

Dialogando com Bhabha (1998), a presença indígena na cidade pode ser vista como um motivo de desordem, pois "seu passado amarrado a traiçoeiros estereótipos de primitivismo e degeneração não produzirá uma história de progresso civil [...]" (p.73). Para o autor, essa

repetibilidade em conjunturas históricas e discursivas mutantes, embasa suas estratégias de individualização e marginalização, produz aquele efeito de verdade probabilistica e predictabilidade que, para o estereótipo, deve sempre estar em excesso do que pode ser provado empiricamente ou explicado logicamente. (Bhabha, 1998, p. 106).

Analisando a mesma situação a partir de Zygmunt Bauman (1998), compreendemos que a presença de índios na cidade causa, além de uma "desordem", também uma "estranheza". Para o sociólogo polonês, a modernidade trouxe consigo uma exaltação da ordem na tentativa de construção de um mundo estável. Sendo assim, "tudo aquilo que estiver fora de 'lugar' ou fora da 'ordem' deve ser retirado do convívio, sendo considerado algo 'sujo', 'imundo', 'impuro', 'estranho' ou 'agente poluidor'" (Vieira, 2015, p. 91).

Apesar do governo não amparar legalmente os indigenas na cidade, presenciamos um crescimento populacional desse segmento nas cidades. Com base nos estudos de Cardoso de Oliveira (1968) com a população Terena na

\footnotetext{
3 Terra indígena é uma categoria jurídica, tendo, portanto, sua origem na definição de direitos territoriais indigenas. Tais direitos foram reconhecidos ao longo da história pelo Estado nacional brasileiro em diversos dispositivos legais (Cavalcante, 2013, p. 44). De acordo com a Constituição Federal de 1988, no artigo 231, as terras indigenas podem ser entendidas da seguinte maneira: " $\$ 1^{\circ}$ - São terras tradicionalmente ocupadas pelos indios as por eles habitadas em caráter permanente, as utilizadas para suas atividades produtivas, as imprescindiveis à preservação dos recursos ambientais necessários a seu bem-estar e as necessárias a sua reprodução física e cultural, segundo seus usos, costumes e tradições. $\S 2^{\circ}$ - As terras tradicionalmente ocupadas pelos índios destinam-se a sua posse permanente, cabendo-lhes o usufruto exclusivo das riquezas do solo, dos rios e dos lagos nelas existentes.
} 
cidade de Campo Grande/MS, a presença de populações indigenas circulando e vivendo no espaço geográfico da cidade pode ser registrada desde o ano de 1920. Mas, é a partir de 1960 que a migração de indígenas para a cidade se intensifica. Muitos que se deslocaram para os centros urbanos vieram em busca de trabalho e de boas escolas para a continuidade dos estudos de seus filhos.

Nos dias atuais, observamos que basta um convite dos parentes, a necessidade de um tratamento de saúde, a falta de escolarização na aldeia ou algum desentendimento ou conflito com lideranças ou membros da comunidade, que muitos indigenas migram para as cidades e provocam um crescimento populacional indigena no espaço urbano. A razão de ir em busca de um projeto de vida é explicada por Melo (2009) da seguinte maneira:

Os indios estão migrando para a cidade buscando o que falta na aldeia - como mercadorias e educação formal principalmente. O 'mundo dos brancos' é representado por bens simbolicamente importantes: as mercadorias e a escola. Ir para a cidade significa escolarização, inserção no mercado de trabalho e, muitas vezes, casamentos interétnicos. (p. 76).

O descolamento de grupos indígenas para o espaço urbano "ganha sentido quando os índios passam a acreditar que a vida na aldeia é inviável, ou quando se dão conta de que a possibilidade de acesso [ao meio urbano] [...] é bastante limitada" (Melo, 2009, p. 87). Assim, analisando o deslocamento dos indígenas, é possivel verificar que o contexto urbano revela um novo mundo a esse grupo, possibilitando a reorganização de um modo de vida. O "estar na cidade" traz a possibilidade de uma alternativa econômica, por meio de outras fontes de rendimento (venda de produtos oriundos da aldeia e de emprego em atividades informais). A cidade parece ter certo prestígio para alguns grupos locais, principalmente aqueles que ocupam algum cargo administrativo na Fundação Nacional do Índio (Funai), na Fundação Nacional de Saúde (FUNASA) e outras instituições que trabalham diretamente no atendimento às populações indígenas.

Os estudos de Cardoso de Oliveira (1968) nos mostram que muitos indigenas possuiam uma representação e uma imagem alienante da cidade, especialmente, quando passavam próximo das lindas casas de vidro. De acordo com o autor, essas "casas de vidro compunham na imaginação indigena uma paisagem citadina impregnada de tal maravilhoso que poucos indios seriam capazes de eludir" (p. 126). No diálogo com Bhabha (1998), percebemos o quanto "esse posicionamento é em si problemático, pois o sujeito encontra-se ou se reconhece através de uma imagem que é simultaneamente alienante e dai potencialmente fonte de confrontação" (p. 119). Já Bauman (2004) chama atenção para o quanto "a vida urbana exerce uma atração constante sobre as pessoas de fora e estas têm como marca registrada o fato de trazerem novas maneiras de ver as coisas e talvez de resolver antigos problemas" (p. 128).

\section{As crianças indígenas na cidade: percepções culturais e brincadeiras de infância}

Após reflexões para melhor compreender esse cenário urbano por onde a criança indígena circula, produz e ressignifica as suas identidades e diferenças, algumas questões acabam surgindo para novas discussões, mas algo que nos perguntamos é: até que idade os povos indigenas na cidade consideram ser criança?

Estudos de Cohn (2005), Tassinari (2007), Nascimento, Aguilera Urquiza e Vieira (2011), Landa (2011) e Vieira (2015) nos convidam a ponderar que a ideia de infância/criança indígena varia de acordo com as diferentes culturas e sociedades. Sobre esse assunto, Cohn (2005) menciona que, entre os índios Xikrin, a criança somente se torna adulta no "momento em que passa a ter uma criança que é sua" (p. 25).

Seguindo nessa mesma direção, Zoia (2010) escreve que, entre os Terena de Mato Grosso ${ }^{4}$, a

\footnotetext{
4 Familias indigenas Terena que saíram do Mato Grosso do Sul e migraram para a região norte de Mato Grosso. Atualmente estão localizados em uma área às margens das rodovias BR 163 e 364. Para mais informações, consultar a tese de doutorado em Educação pela UFG de Alceu Zoia intitulada A Comunidade Indigena Terena do Norte de Mato Grosso: infância, identidade e educação.
} 
criança indigena é considerada criança até os 10 anos, pois, a partir dessa idade, ela "já começa a ter malícia, então já pode ser considerado um rapazinho" (p. 13). Mas, é importante ressaltar a partir do trabalho de Oliveira (2014) que entre os povos indígenas não existe o termo adolescente. Segundo o autor, "a criança sai da fase de criança e vai para a vida adulta, pois com 13 e 15 anos muitas meninas estão dando à luz um bebê" (p. 99).

Viera (2015) escreve que entre os indígenas em contexto urbano de Campo Grande, muitos também seguem essa mesma lógica apontada pelos autores que estudam a infância/criança indigena. Ainda segundo o autor, existem na cidade muitas familias indigenas que já vivem há tempo e negam essa lógica indigena.

Caminhando pelo universo infantil das crianças indigenas na cidade, mais precisamente refletindo nossas experiências enquanto pesquisadores com crianças, observamos que muitas das crianças que residem no espaço urbano vivenciam situações comuns do contexto das Terras Indigenas. Assim como no espaço rural, as crianças indigenas urbanas são observadoras e atuantes, pois perambulam por todos os espaços da comunidade, conhecem todos os parentes, casas, lugares, a geografia do bairro e são as primeiras que recebem as pessoas na aldeia (Nascimento, Urquiza, \& Vieira, 2011; Cohn, 2005). Isso nos mostra o quanto "ela interage ativamente com os adultos e as outras crianças, com o mundo, sendo parte importante na consolidação dos papéis que assume e de suas relações" (Cohn, 2005, p. 28).

Ainda nesse contexto, verificamos 0 quanto a criança indígena tem o respeito e o reconhecimento de sua comunidade. Ela tem uma liberdade de escolha e decisão muito diferente das crianças não indígenas. Muitos indigenas as veem como produtoras de muitos conhecimentos, até mais que os adultos; por isso, possuem um lugar significativo dentro da cultura.

Nossas experiências de pesquisa nos apresentam o quanto as crianças aprendem com os mais velhos imitando e observando os adultos, principalmente pelo fato de estarem junto, sempre perto de uma conversa ou atividade. Durante algumas visitas as aldeias indigenas urbanas, de Campo Grande e região, no estado de Mato Grosso do Sul, conversando com as lideranças, as crianças sempre estavam nas proximidades dos adultos. Primeiramente chegavam as crianças da casa, sentavam-se no chão para brincar; depois chegavam mais uma, duas; quando percebiamos, havia muitas outras em volta observando a conversa.

O fato da criança indigena sempre estar junto observando os adultos revela que ela está aprendendo as regras de convívio social. Com base nos estudos de Cohn (2005), Tassinari (2007, 2012), Nascimento, Urquiza e Vieira (2011) e Vieira (2015) os pais são os responsáveis pela socialização das crianças, principalmente, por integrá-las na vida da comunidade e transmitir os valores e as tradições do grupo, mas é importante ressaltar que essa responsabilidade também é dividida com os parentes e as pessoas com que se relacionam cotidianamente.

Outra situação muito observada durante as caminhadas pelas aldeias urbanas é o cuidado entre os irmãos. Segundo Landa (2011), os irmãos mais velhos são aqueles que primeiro socorrem os mais novos quando se machucam, pois "possuem uma série de zelos que não são de responsabilidade exclusiva da mãe e/ou adultos cuidadores" (p. 66). Ao longo de nossas experiências, foi comum ver essa prática nas aldeias urbanas e nas escolas municipais com estudantes indigenas. Muitas vezes, o irmão mais velho puxando pelas mãos os mais novos, todos enfileirados.

Muitos que desconhecem a cultura indigena podem mencionar que essa situação é uma prática também comum na cultura ocidental, mas a diferença é que na sociedade não indigena o contexto econômico e social das famílias contribuiu para essa nova organização. Além do cuidado dos irmãos mais novos, os filhos mais velhos ainda precisam ajudar nas atividades domésticas. Na cultura indígena, essa prática é uma forma de preparar a criança para a vida adulta, ensinando-lhe a maneira de cuidar e de zelar por seus irmãos (Cohn, 2005).

Sobre esse universo, Tassinari (2012) escreve 
que os índios reconhecem a autonomia e a capacidade de decisão das crianças indígenas, pois elas "são elementos chave na socialização e na interação de grupos sociais" (p. 281). Segundo a autora, os adultos ainda observam nas crianças "as potencialidades que as permitem ocupar espaços de sujeitos plenos e produtores de sociabilidade" (Tassinari, 2012, p. 281). Para Woodward (2000), isso só tem sentido porque a cultura "nos propicia os meios pelos quais podemos dar sentido ao mundo social e construir significados" (p. 41).

No diálogo com Woodward (2000) reforçamos ainda mais as palavras de Cohn (2005) quando menciona que "as crianças não são apenas produzidas pelas culturas, mas também produtoras de cultura. Elas elaboram sentidos para o mundo e suas experiências compartilhando plenamente de uma cultura" (p. 35).

As crianças indígenas na cidade, além do ambiente da aldeia e da familia, circulam por diferentes espaços da cidade, frequentam escolas, creches, igrejas, shoppings, clubes, praticam atividades esportivas e realizam cursos profissionalizantes em diferentes instituições de ensino. Assim como na Terra Indigena, as crianças em contexto urbano "acabam repassando aos pais o que viram e ouviram, desempenhando o papel de facilitadores de comunicação" (Pereira, 2011, p. 97).

O índio Terena 2, morador da aldeia indigena urbana Darci Ribeiro, confirmou a situação relatando:

Tenho dificuldade de saber as noticias da aldeia, somente no final de semana quando converso com os amigos. Trabalho o dia todo, mas sempre quando acontece alguma coisa na aldeia ou aparece uma pessoa nova na casa ou na região os meus filhos falam para nós. Como eles andam mais, eles sabem mais. (Índio Terena 2, comunicação pessoal, 24 de setembro de 2013). ${ }^{5}$
Retornando ao assunto dos diferentes ambientes por onde circulam as crianças indigenas na cidade, tivemos a oportunidade de escutar por meio do diálogo com algumas lideranças da aldeia indigena urbana, especificamente de Campo Grande/ MS, que as crianças indigenas na cidade estão em "desvantagem", principalmente porque estão perdendo o contato diário com o seu povo, sua cultura, sua tradição e sua vida comunitária. Por esse motivo, os pais e os avós procuram dedicar um tempo maior para sempre ouvir as crianças, brincar com elas e contar histórias e mitos. Sempre que podem, despertam o interesse das crianças em conhecer mais sobre a cultura e as tradições.

Segundo Vieira (2015) nem todas as famílias têm esses momentos com as crianças. Em algumas familias, o tempo acaba sendo limitado, pois os pais trabalham em periodo integral e as crianças ficam na escola e nos projetos ${ }^{6}$ realizados nas aldeias urbanas. Outras, mesmo tendo tempo para o diálogo com as crianças, acabam não se importando, pois a vida na cidade parece não precisar desses outros conhecimentos e saberes.

Apesar de certa similaridade do cotidiano das crianças indígenas com o das não indígenas, as observações realizadas durante as pesquisas e as conversas com os professores indigenas moradores nessas comunidades urbanas mostram que as crianças indigenas se sentem, em algumas situações, limitadas, principalmente com relação a determinadas atividades e brincadeiras. Sobre essa situação, apresentamos a fala de um indigena, morador da aldeia indigena urbana Darci Ribeiro, que menciona a dificuldade de espaço para brincar das crianças:

As nossas crianças indigenas urbanas ficam em um espaço muito limitado. Muro aqui, muro ali, muro na frente. Não pode sair, fica em casa. Eu vejo com os meus netos. Eles não têm aquela liberdade. Eu tive essa liberdade. Na aldeia

\footnotetext{
5 Entrevista realizada em 24 de setembro de 2013, coordenada pelo pesquisador Carlos Magno Naglis Vieira, no projeto de pesquisa: A cosmovisão e as representações das crianças indigenas no Mato Grosso do Sul: as relações entre a pedagogia do cotidiano e a escola. Financiamento CNPq.

6 Cito o projeto Córrego Bandeira, desenvolvido em parceria com o Instituto Nacional de Desenvolvimento do Desporto e o Instituto Ayrton Senna (IAS). O projeto Córrego Bandeira iniciou suas atividades no ano de 1996 nas dependências da Universidade Federal do Mato Grosso do Sul com crianças e adolescentes de bairros carentes. Somente no ano de 2000 começou um trabalho com crianças indigenas da aldeia indigena urbana Marçal de Souza. No projeto as crianças desenvolvem atividades que são "organizadas por área de conhecimento e realizadas em oficinas, esporte e/ou recreação, saber (apoio pedagógico), dança, musicalização, informática e psicologia para auxiliar o educando em seu desenvolvimento interpessoal" (Bittar, 2011, p. 55).
} 
as crianças acordam já correndo, vão na lagoa, vão tomar banho. Isso que falo que aqui é muito limitado. (Índio Terena 1, comunicação pessoal, 14 de maio de 2013). ${ }^{7}$

Diferente do que apresenta o sociólogo Zygmunt Bauman (2004), segundo o qual os muros "cercam-se para ficar 'fora' da excludente, desconfortável, vagamente ameaçadora e dura vida da cidade - e 'dentro' do oásis de calma e segurança" (p. 131), os muros, por mais que estejam localizados no espaço da aldeia, representam uma segurança, mas também podem significar um impedimento, um silenciamento e uma subalternização com relação ao modo tradicional de ser indigena no espaço da cidade.

A infância que se passa na cidade tem muitas restrições e exige atenção e cuidado, comenta um acadêmico indígena Terena. Por conta dessa situação, presenciamos a participação de muitas crianças indigenas em diferentes espaços não escolares na cidade, ou seja, frequentando projetos promovidos por associações, escolas, universidades e instituições públicas.

As crianças indigenas que frequentam esses projetos têm uma boa aceitação, principalmente, porque proporcionam o aprendizado de muitos conhecimentos e não deixam que elas fiquem circulando pelas ruas. No diálogo com os moradores indígenas das aldeias indígenas urbanas, essa situação foi mencionada algumas vezes, principalmente porque muitos pais são questionados por moradores não indígenas sobre a liberdade que dão aos seus filhos. Durante as pesquisas identificamos que muitos patrícios indígenas também se incomodam com a presença das crianças na rua. Segundo relato, existem inúmeros discursos, como:

Aquelas mães não se preocupam com as crianças nas ruas da aldeia. Essa familia que chegou a pouco tempo da aldeia na Terra indigena acha que a mesma coisa. Aqui é perigoso, é di-

\begin{abstract}
ferente. Tem muitos carros correndo, caminhões passando, motoqueiro xingando. É diferente da nossa aldeia, o carro passa muito pouco. As mães precisam cuidar as crianças com as pipas, elas não olham. Também tem criança que entra na casa do vizinho e ele não gosta. Olha lá, as crianças estão brincando com a areia e a pedra do vizinho. Ele está trabalhando e quando chega briga com as crianças (IIndio Terena 3, comunicação pessoal, 13 de agosto de 2013). ${ }^{8}$
\end{abstract}

No diálogo com o indígena, fica evidente que muitas familias indigenas já ressignificaram os conceitos de liberdade e brincadeira. Como se observa no discurso acima, muitos pais não permitem que suas crianças brinquem em lugares considerados "perigosos" e a uma distância em que não consigam protegê-las e controlá-las. Essa situação mostra o quanto a identidade indígena em contexto urbano está sendo ressignificada na interação com a sociedade não indigena. De acordo com Hall (2004), o sujeito pode ser "formado e modificado num diálogo contínuo com os mundos culturais 'exteriores' e as identidades que esses mundos oferecem" (p. 11)

Apesar desse controle exercido por alguns pais, observamos que as crianças indigenas ainda definem suas brincadeiras e o modo de brincar, bem como o momento de mudar de brincadeira, o que mostra o modo próprio de ser das crianças indígenas no espaço da cidade (Sobrinho, 2009; Cohn, 2005; Lopes da Silva, Macedo \& Nunes, 2002; Nascimento, Aguilera Urquiza \& Vieira, 2011). Assim como Sobrinho (2009), percebemos que "as crianças reproduzem uma série de situações que elas observam no entorno da comunidade e principalmente nas práticas a que são submetidas na escola, mas sempre as ressignificando" ( $p .178$ ).

Durante as caminhadas pelas aldeias, sempre percebemos as crianças brincando de corrida, de esconde-esconde, soltando pipa, andando de bicicleta, brincando de casinha, jogando bolinha de gude (bolita) e futebol. Assim como

\footnotetext{
Entrevista realizada em 21 de maio de 2013, coordenada pelo pesquisador Carlos Magno Naglis Vieira, no projeto de pesquisa: A cosmovisão e as representações das crianças indigenas no Mato Grosso do Sul: as relações entre a pedagogia do cotidiano e a escola. Financiamento CNPq.

8 Entrevista realizada em agosto de 2013, coordenada pelo pesquisador Carlos Magno Naglis Vieira, no projeto de pesquisa: A cosmovisão e as representações das crianças indigenas no Mato Grosso do Sul: as relações entre a pedagogia do cotidiano e a escola. Financiamento CNPq.
} 
Lopes da Silva, Macedo e Nunes (2002), também observamos que existe produção de identidade(s) e diferença(s) por meio das brincadeiras entre as crianças indigenas e não indígenas, seja na escola ou no espaço da aldeia urbana.

O futebol foi a brincadeira que por mais vezes identificamos entre as crianças. Não sabemos ao certo quantas partidas de futebol tivemos a oportunidade de presenciar, mas o que sempre nos chamava atenção era a quantidade de crianças dentro e fora do campo. Além disso, havia sempre crianças chegando para brincar, vestidas com camisas de times do futebol nacional, com o uniforme da escola e mesmo sem camisa.

Uma situação vivenciada durante as partidas de futebol foi a associação que muitas crianças indígenas faziam com um determinado time de futebol e o jogador do momento. Entre os principais nomes de jogadores que aparecem com frequência estão os de Neymar, Messi, Ronaldinho e Robinho. Essa associação com jogadores mostra que "as posições que assumimos e com as quais nos identificamos constituem nossas identidades" (Woodward, 2000, p. 55).

Entre as meninas, além do jogo de futebol e da prática de esconde-esconde, identificamos que muitas gostam de brincar de casinha, no fundo da casa, mais especificamente no quintal, brincadeira também registrada por Sobrinho (2009) entre as crianças indigenas Satere Mawé em Manaus/AM. Observamos que, durante as brincadeiras, elas cercavam o local com cadeiras, latas e outros objetos que ficavam no quintal. As comidas fictícias eram feitas de água, terra e folhas de árvores e elas, ainda, tinham um trato de chamar uma à outra de mamãe e filhinha. A mamãe era sempre a criança de mais idade, e os filhos eram as crianças menores. Nessa brincadeira não presenciamos a participação dos meninos brincando entre as meninas, o que indica que se trata de uma brincadeira feminina.

Ainda durante a observação e as experiências realizadas, verificamos que outra brincadeira muito realizada pelas crianças indigenas nos quintais das casas é a de ensinar as outras crianças. A escolinha, como é denominada essa brincadeira pelas crianças, é sempre praticada muito mais pelas meninas do que pelos meninos. o que despertou o nosso olhar nessa atividade é o modo como brincam. Sempre há uma criança no comando, na figura da professora, as demais estão sentadas no chão e as cadeiras servem de carteiras. Ao contrário da escola, elas não estão enfileiradas, mas sim espalhadas pelo quintal. Conversam um pouco mais e copiam o conteúdo que é explicado pela professora.

A brincadeira de escolinha representa o desejo que muitas crianças têm de ser professor. De acordo a fala do indígena 3, na cidade, "muitas crianças que chegam da aldeia desejam ser professor, gostam de ensinar. Perguntam para mim se precisa estudar bastante. Sempre digo que estou estudando" (Índio Terena 3, comunicação pessoal, 13 de agosto de 2013). Vieira (2015) realizando um diálogo com Silva (2000), nos apresenta o quanto a representação está ligada à produção da identidade e da diferença. Ainda, segundo Silva (2000),

A identidade e a diferença são estreitamente dependentes da representação. É por meio da representação, assim compreendida, que a identidade e a diferença adquirem sentido. É por meio da representação que, por assim dizer. a identidade e a diferença passam a existir. (Silva, 2000, p. 91).

Segundo Lopes da Silva, Macedo e Nunes (2002), as brincadeiras "são momentos fundamentais para compreendermos o universo infantil, pois as crianças sabem coisas que, muitas vezes, sequer nos passariam pela cabeça" (p. 79). As autoras ainda descrevem que

$$
\begin{aligned}
& \text { essas brincadeiras estabelecem entre } \\
& \text { si uma relação de complementaridade, } \\
& \text { refletindo momentos de interiorização } \\
& \text { e exteriorização, de concentração e } \\
& \text { de expansão, de descoberta e de re- } \\
& \text { afirmação, de vivências individuais e } \\
& \text { coletivas. (Lopes da Silva, Macedo, \& } \\
& \text { Nunes, 2002, p. 79). }
\end{aligned}
$$

Além das brincadeiras mencionadas anteriormente, observamos que muitas crianças indigenas já incorporaram o mundo dos brancos e, em vez de praticar esportes e outras brincadeiras, 
preferem ficar jogando videogame e fliperama nos estabelecimentos próximos da casa. Durante conversas informais com as lideranças das aldeias indigenas urbanas Marçal de Souza e Darci Ribeiro, verificamos que a prática de jogar videogame e fliperama tem sido um problema na aldeia, pois tem provocado um certo desconforto para os indigenas. Diante dessa situação percebemos o quanto somos perturbados e afetados pelos Outros e o quanto as identidades são resultado das relações sociais e são produzidas por inúmeras articulações, contatos que se cruzam ou encontram (Bhabha, 1998; Hall, 2003). Ou seja, segundo Woodward (2000), "diferentes contextos sociais fazem com que nos envolvamos em diferentes significados sociais" (p. 30).

A prática de jogar videogame e fliperama entre as crianças indigenas em contexto urbano é resultado da globalização. Essa, por sua vez, "produz diferentes resultados em termos de identidade" (Woodward, 2000, p. 21), provocando um certo distanciamento da identidade no tocante à comunidade e à cultura local, e com o envolvimento podem surgir novas posições de identidade (Woodward, 2000).

Além das muitas brincadeiras tradicionais dos povos indígenas realizadas na cidade, observamos que muitos jovens estão se sentindo animado pelo fato de estarem aprendendo as danças tradicionais. Em Campo Grande/MS e Dourados/ MS eles estão despertando o interesse pela cultura e realizando ensaios para apresentações de dança, como o da ema (Kipaé), a dança do bate pau ${ }^{9}$ e o sambo. ${ }^{10}$

As crianças indigenas estão sempre circulando por diferentes espaços na aldeia e fora dela, assim como na Terra Indígena. Como estão sempre caminhando e brincando em grupo, elas frequentam espaços no interior da aldeia que servem como locais de socialização, trocas e diálogos entre os pares, o que contribui para o fortalecimento da cultura e da tradição indígena no espaço da cidade.
Estudos realizados com crianças indígenas evidenciam que elas aprendem entre si, ressignificam os saberes ditos tradicionais, são agentes na produção da história e dos conhecimentos tendo em vista os movimentos que cada grupo faz nas relações internas e externas que vivem no dia a dia (Nascimento, Aguilera Urquiza, \& Vieira, 2011; Cohn, 2005; Lopes Silva, Macedo, \& Nunes, 2002; Tassinari, 2007, 2012).

Diante dessa e de outras situações, verificamos que as crianças são agentes históricos e têm os seus modos próprios de atribuir sentidos, interpretar, recriar o mundo onde vivem, participando ativamente na reorganização de seus sistemas culturais. A criança não é um ser invisivel nas relações indigenas, nem excluida e subalternizada nas relações internas. No cotidiano das crianças indigenas em contextos urbanos essa realidade parece ser também uma referência, apesar da "urbanidade" a que estão submetidas. No entanto, é importante e necessário ampliar as percepções sobre as ressonâncias que as relações entrelugares, ou seja, comunidade indigena/urbana, produzem na construção das identidades.

\section{As crianças indígenas no espaço escolar da cidade}

Com o crescimento das migrações indígenas para a cidade houve um aumento de estudantes indigenas Terena (crianças) nas escolas urbanas. Esse intenso movimento de crianças indigenas circulando pelos espaços escolares fez com que direcionássemos nossos olhares para dentro das escolas, procurando perceber as relações que as crianças estabelecem com outros autores e as tensões presentes nesses espaços.

O intenso convívio com as crianças Terena, dia a dia nas dependências das escolas, proporcionou a nós pesquisadores uma maior sensibilidade, principalmente em ver detalhes, olhares, gestos, silêncios, discursos, e contribuiu para

\footnotetext{
9 De acordo com Espíindola (2013), "a dança da ema tem tudo a ver com aquela ave grandona do Pantanal [...]; à medida que ela vai sendo feita, ela é demonstrada em sete coreografias. Então, ela é muito riquissima, ela é muito bonita [...]. E no final [...], o cacique [...] que comanda l...] durante a dança é elevado em cima dos bambus, em cima como se fosse a vitória do cacique, ele teve a vitória do seu povo na conquista de alguma coisa. Ás vezes, essa dança é feita durante um casamento, sempre em época de festividade (p. 42).

10 Uma arte, um jogo, uma defesa corporal realizado pelos Guarani e Kaiowá.
} 
aprender a ouvir e ver as crianças indigenas. É importante mencionar que esse olhar mais atento e direcionado para as crianças Terena na cidade foi se construindo no decorrer do trabalho de campo, mais especificamente quando experimentamos as diferentes formas de se fazer pesquisa e com isso nos tornamos pesquisadores com crianças.

$\mathrm{Na}$ tentativa de aprender a ouvir as vozes dessas crianças que estão nessa fronteira da exclusão e circulando com elas pelos espaços das escolas, percebemos com o passar do tempo, conforme adentrávamos no campo de pesquisa e direcionávamos mais os nossos olhares, que o clima de harmonia deu espaço a tensões, incompreensões e conflitos que começaram a aflorar com mais frequência. $O$ que parecia ser homogêneo começou a se fragmentar. Assim como na pesquisa de Santos (2014), as manifestações se apresentavam mais aparentes, sempre no intervalo (recreio), nas aulas de Educação Física e na saída da escola.

As manifestações, sempre quando apareciam, estavam marcadas com um certo teor de estereotipia, preconceito e discriminação, em que se transforma o "outro", até há pouco tempo amigo, em um sujeito colonial, inferior, ignorado e excluído. Segundo Skliar (2003),

O outro colonial e maléfico é um corpo sem corpo. Uma voz que fala sem voz. Que diz sem dizer. Que foi massacrado e que segue sendo culpabilizado por seu próprio massacre. Uma representação do outro que gira em torno de um eu completo, natural, concêntrico, onisciente, disseminado, Todo-Poderoso (p. 43).

Esse preconceito é reproduzido ao ser amparado por relações de poder, em que se vê neles uma inferioridade, ou seja, um olhar armado de superioridade, regulação e controle que define para onde olhar (Skliar, 2003). Trata-se de um discurso hegemônico produzido dentro da óptica da colonialidade que silencia e oculta a diferença e impõe e reafirma o seu imaginário. Um discurso em que a imagem do indio ainda continua associada a um estereótipo que causa desordem, abre as fantasias mais selvagens da posição de dominação e posiciona o sujeito em um determinado lugar social e cultural (Bhabha, 1998).

Nesse caso, o estereótipo pode ser compreendido como discurso que é produzido no cotidiano das pessoas e está fixado, preso e naturalizado na identidade do sujeito. É um aspecto importante do discurso colonial, pois procura, de alguma forma, negar e camuflar a percepção da diferença do Outro (Bhabha, 1998).

Diante das tensões e conflitos com os colegas de escolas, tivemos a oportunidade de observar que as crianças Terena para tentar se livrar de certas situações, como a mencionada anteriormente, mascaram, boicotam, silenciam e omitem sua identidade e diferença indígena. Essas atitudes das crianças indígenas podem ser entendidas como um processo de negociação (Bhabha, 1998). O que isso significa? As crianças Terena na escola negociam suas identidades, ora se identificando como indio, ora assumindo outra identidade. Sendo assim, dependendo da situação em que se encontra, ela poder ser indígena, branco, negro, paraguaio, entre outros. De acordo com Bhabha (1998), ela pode ser isto e aquilo, o que, para estudiosos de outros campos teóricos, pode ser considerado como uma crise de identidade.

Vieira (2015) amparado em Hall, descreve sobre o assunto, mostrando que "a identidade somente se torna uma questão quando está em crise, quando algo que se supõe como fixo, coerente e estável é deslocado pela experiência da dúvida e da incerteza" (Hall, 2004, p. 09). Observo que o silenciamento e a negação desses indígenas são uma forma de boicote e mascaramento; assim, no momento em que eles se apropriam de elementos culturais, novos sentidos e significados são produzidos, acarretando e fomentando o que Bhabha (1998) denomina de negociação em vez de negação.

Amparado em autores como Vieira (2015), Tassinari (2012) e Sobrinho (2009), entendemos que a criança indigena, no momento em que negocia com o grupo de crianças não indigenas, está produzindo e fabricando uma nova identidade e diferença. Segundo Bhabha (1998), isso acaba acontecendo devido aos espaços de entrelugares que "fornecem o terreno para a elaboração de estratégias de subjetivação - singular ou coletiva - 
que dão início a novos signos de identidade" (p. 20).

Entre as manifestações das crianças indigenas nas escolas, estão ainda a revolta e a rebeldia com relação a algumas situações vivenciadas, principalmente quando sofrem algum tipo de discriminação ou preconceito e são contrariadas por alguma decisão que não agrada, como, por exemplo, a separação do grupo de meninas. Mas, em muitas situações, os professores não indigenas e a direção das escolas não conseguem identificar que a rebeldia das crianças indigenas acontece por conta de ações que extrapolam a imagem da identidade e da diferença indígena.

No rastro dessa discussão, observamos a partir do intenso convívio com as crianças Terena que residem nas duas aldeias indigenas urbanas de Campo Grande, que no momento em que se negocia com o grupo de crianças não indígenas, está se produzindo e se fabricando uma nova identidade e diferença. Segundo Bhabha (1998), isso acaba acontecendo devido aos espaços de entrelugares que "fornecem o terreno para a elaboração de estratégias de subjetivação singular ou coletiva - que dão início a novos signos de identidade" (p.20).

Em outras palavras, verificamos que mesmo antes de entrar no espaço escolar, a identidade da criança indígena já vem sofrendo deslocamentos. Muitos desses deslocamentos ocorrem a partir do contato com outro(s), das negociações que ela realiza e das tensões e dos conflitos vividos no seu dia a dia. Em outras palavras, o que se percebe é o fato de que as identidades e as diferenças são construídas em meio a relações de poder. Assim, observa-se que não é só a escola que contribui para o silenciamento e o enfraquecimento da identidade e da diferença da criança Terena, mas outros fatores contribuem para que isso ocorra.

\section{Referências}

Albuquerque, Marcos Alexandre dos Santos. (2011). O regime imagético Pankararu: tradução intercultural na cidade de São Paulo. Tese (Doutorado em Antropologia). Universidade Federal de Santa Catarina, Florianópolis.

Baumann, Zygmunt. (1998). O mal estar da pós-modernidade. Rio de Janeiro: Jorge Zahar.
Baumann, Zygmunt. (2004). Amor liquido: sobre a fragilidade dos laços humanos. Rio de Janeiro: Jorge Zahar Editor.

Bhabha, Homi K. (1998). O local da cultura. Belo Horizonte: Editora da UFMG.

Cardoso De Oliveira, Roberto. (1968). Urbanização e tribalismo: a integração dos indios Terena numa sociedade de classe. Rio de Janeiro: Jorge Zahar.

Castro-Gómez, Santiago. (2005). Ciências sociais, violência epistêmica e o problema da "invenção do outro". In Lander, Edgardo (Org.). A colonialidade do saber: eurocentrismo e ciências sociais. Perspectivas latino-americanas (pp. 169-186). Colección Sur Sur, CLACSO, Ciudad Autónoma de Buenos Aires, Argentina.

Cavalcante, Thiago Leandro Vieira. (2013). Colonialismo, território e territorialidade: a luta pela terra dos Guarani e Kaiowá em Mato Grosso do Sul. Tese (Doutorado em História). Faculdade de Ciências e Letras, Universidade Estadual Paulista, Assis. https:// doi.org/10.4025/6cih.pphuem.244.

Cohn, Clarice. (2005). Antropologia da criança. Rio de Janeiro: Jorge Zahar Ed.

Espindola, Micheli Aline Jorge. (2013). Jovens Terena na cidade de Campo Grande (MS): politica e geração. Dissertação (Mestrado em Antropologia). Universidade Federal do Rio Grande do Norte, Natal.

Hall, Stuart. (2004). A identidade cultural na pós-modernidade. Rio de Janeiro: DP\&A.

Kramer, S. (2010). Infância, educação e critica da cultura em Walter Benjamin. In Garcia, Regina Leite (Org.). Diálogos cotidianos (pp. 187-194). Petrópolis/ RJ, Rio de Janeiro: DP et alii/ FAPERJ, 2010. v. 1.

Landa, Beatriz dos Santos. (2011) Crianças Guarani: atividades, uso do espaço a formação do registro arqueológico. In Nascimento, Adir Casaro; Urquiza, Antônio Hilário Aguilera, \& Vieira, Carlos Naglis (Org.). Criança indigena: diversidade cultural, educação e representações sociais (pp. 45-74). Brasilia, DF: Liber Livros.

Lopes da Silva, A., Macedo, A. V. L. da Silva, \& Nunes, A. (Orgs.). (2002). Crianças indigenas: ensaios antropológicos. São Paulo: Global.

Melo, Juliana. (2009). Identidades fluidas: ser e perceber-se como Baré (Aruak) na Manaus Contemporânea. Tese (Doutorado em Antropologia Social). Universidade de Brasília, Brasilia, DF.

Nascimento, Adir Casaro, Aguilera Urquiza, Antônio Hilário, \& Vieira, Carlos Magno Naglis. (2011). A cosmovisão e a representação das crianças indígenas Kaiowá e Guarani: o antes e depois da escolarização In Criança indigena: diversidade cultural, educação e representações sociais (pp. 21-44). Brasilia, DF: Liber.

Oliveira, Assis da Costa (2014). Indígenas crianças, crianças indigenas: perspectivas para construção da doutrina da proteção plural. Curitiba: Juruá. 
Pereira, Levi Marques (2011). Socialização da criança kaiowá e guarani: formas de socialidade internas às comunidades e transformações históricas recentes no ambiente de vida. In Nascimento, Adir Casaro, Aguilera Urquiza, Antônio Hilário, \& Vieira, Carlos Magno Naglis (Org.). Criança indigena: diversidade cultural, educação e representações sociais. (pp. 75112). Brasília, DF: Liber.

Santos, Vanúbia Sampaio dos (2014). Expressões identitárias no espaço escolar: um estudo com estudantes indigenas de escolas públicas urbanas de Ji-Paraná, Rondônia. 2014. Dissertação (Mestrado em Educação). Universidade Federal do Mato Grosso, Cuiabá

Skliar, Carlos (2003). Pedagogia (improvável) da diferença: se o outro não estivesse aí? Rio de Janeiro: D\&A

Silva, A. L., Macedo, A. V., \& Nunes, A (2002). Crianças indigenas, ensaios antropológicos. São Paulo: MARI/ FAPESP/Global.

Silva, Tomás Tadeu da, Hall, Stuart, \& Woodward, Kathryn (Org.) (2000). Identidade e diferença: a perspectiva dos Estudos Culturais. (3. ed). Petrópolis: Vozes.

Silva, Zilmar Lima da Silva (2015). Território e territorialidades indigenas na cidade de Manaus. In Gestão do conhecimento e território indigenas: por uma geografia participante. Manaus: Reggo Edições.

Sobrinho, Roberto Sanches Mubarac (2009). Vozes infantis: as culturas das crianças Sateré-Mawé como elementos de (dês) encontros com as culturas da escola. Tese (Doutorado em Educação). Universidade Federal de Santa Catarina, Florianópolis.

Tassinari, A. M. I. (2007) Concepções indigenas de infância no Brasil. Revista Tellus, ano 07, 13, 11-25.

Tassinari, A. M. I., \& Grando, Beleni Saléte; Albuquerque, Marcos Alexandre dos Santos (Org.). (2012). Educação indigena: reflexões sobre as noções nativas de infância, aprendizagem e escolarização. Florianópolis: Editora UFSC

Vieira, Carlos Magno Naglis. (2015) A criança indigena no espaço escolar de Campo Grande/MS: identidade e diferença. 2015. Tese (Doutorado em Educação). Universidade Católica Dom Bosco, Campo Grande.

Woodward, Kathryn. (2000) Identidade e diferença: uma introdução teórica e conceitual. In Silva, Tomaz Tadeu da (Org.). Identidade e diferença: a perspectiva dos estudos culturais (pp. 7-72). Petrópolis: Vozes

Zoia, Alceu, \& Peripolll, Odimar J. (2010, junho/ dezembro). Infância indigenas e outras infâncias. Espaço Amerindio, 04, 01-16. https://doi. org/10.22456/1982-6524.12647.

\section{Carlos Magno Naglis Vieira}

Doutor em Educação pela Universidade Católica Dom Bosco (UCDB, Campo Grande, MS, Brasil), professor da Universidade Católica Dom Bosco (UCDB) em Campo Grande, MS, Brasil.

\section{Adir Casaro Nascimento}

Doutora em Educação pela Universidade Estadual Paulista Júlio de Mesquita Filho (UNESP, Marilia, SP Brasil), professora da Universidade Católica Dom Bosco (UCDB) em Campo Grande, MS, Brasil.

\section{Endereço para correspondência}

Carlos Magno Naglis Vieira

Universidade Católica Dom Bosco

Av. Tamandaré, 6000, Bloco D, piso superior

Jardim Seminário, 79117-010

Campo Grande, MS, Brasil

Adir Casaro Nascimento

Universidade Católica Dom Bosco

Av. Tamandaré, 6000, Bloco D, piso superior

Jardim Seminário, 79117-010

Campo Grande, MS, Brasil 